\title{
Shocks, tipping points and last straws: Turnover decision making in a post-disaster context
}

$\underline{\text { Authors }}$

V Nilakant, U. of Canterbury, ven.nilakant@canterbury.ac.nz

Russell Wordsworth, U. of Canterbury, russell.wordsworth@canterbury.ac.nz

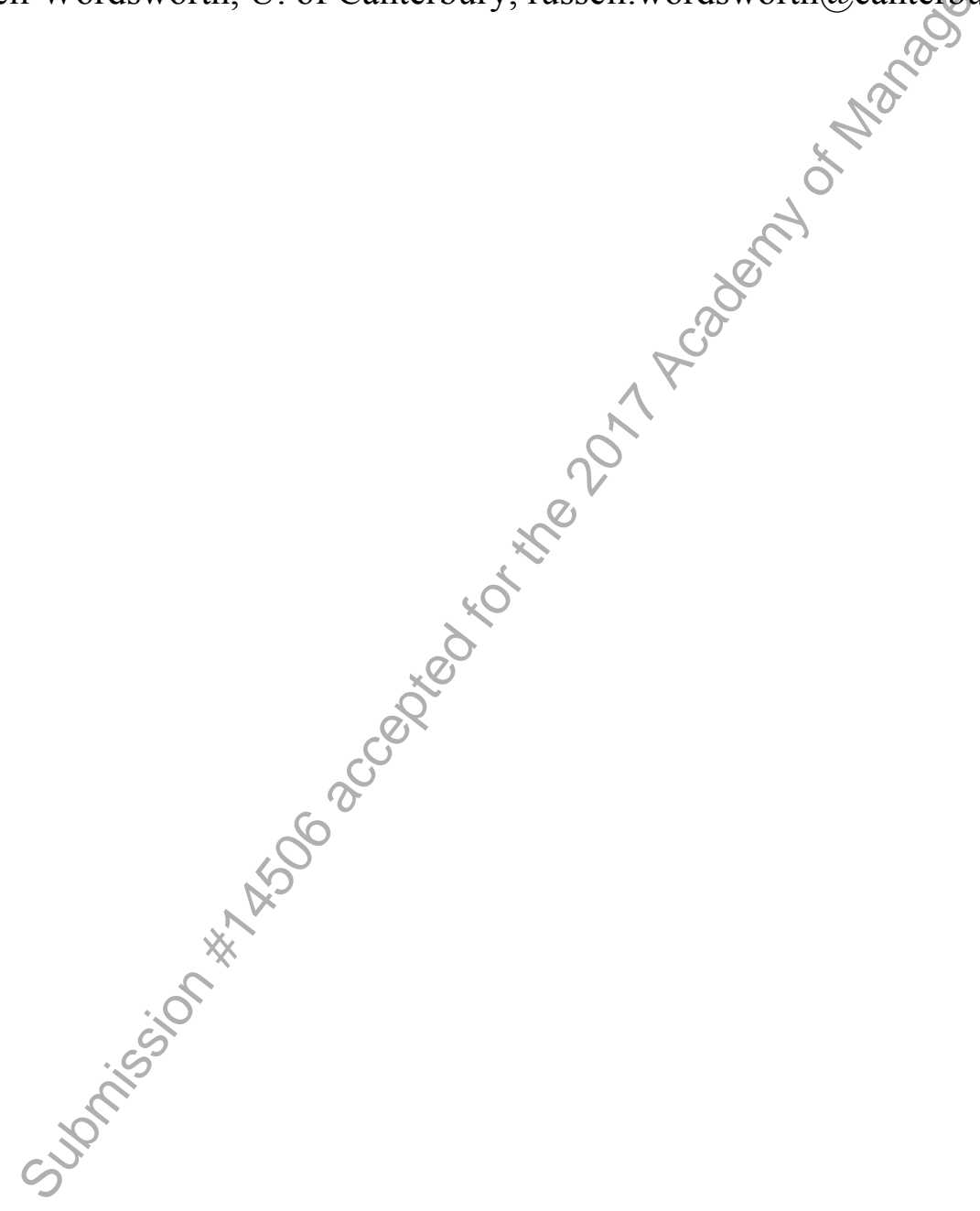




\title{
Shocks, Tipping Points and Last Straws: Turnover Decision Making in a post-disaster context
}

\begin{abstract}
This paper presents a leaver-centric theory of employee turnover decision making following a significant external shock. Data was collected from in-depth interviews with 31 leavers in four organisations in a region that was hit by a major natural disaster. What was distinctive about the context was that the major shock was followed by a series of smaller shocks that shaped individuals' decision to leave. Using grounded theory methods the study identifies engaging in critical reflection as a core category that differentiated the decision-making processes of participants. The paper presents a new typology of leaving consisting of four distinct decision paths. The choice of path was shaped by four factors which emerged from the data: (1) preshock motivational state; (2) decision difficulty; (3) experienced shock magnitude; and (4) the availability of resources. The paper addresses several shortcomings in the extant literature on employee turnover. The four paths together with the four contextual influences represent a grounded theory of turnover and are a significant contribution to this literature.
\end{abstract}

\section{Keywords:}

Voluntary turnover; decision making; shock; critical reflection; grounded theory 
Donald Trump's victory in the 2016 US presidential election was described by Time Magazine as the most shocking in modern political history (Berenson, 2016). The win for Trump ran counter to almost every poll and spurred intense reactions throughout the US. One such reaction was evidenced in the dramatic increase in traffic to the immigration websites of Canada and New Zealand. Canada's immigration website crashed even before the final election result was in, and remained down for several days following. Visits to the New Zealand immigration site by US nationals reached 56,300 in the 24 hour period following the election result, compared with a daily average of 2,300 (Abrams, 2016). Anecdotally, these figures appear to suggest that the shock of a Trump victory was sufficiently jarring to lead many to consider leaving the United States. While a mass exodus to these countries is highly unlikely, there will no doubt be people who will follow through with their plans to leave the US. This raises interesting questions for turnover scholars. What role do significant and commonly experienced extra-organizational shocks play in initiating turnover decision making? Why do some employees who have initial strong reactions to a shock leave, and yet not others? How do shock-induced decisions to leave unfold over time? Such questions have to date not typically been addressed in the literature on employee turnover.

This paper presents a theory of voluntary turnover decision making that is grounded in the context of a significant extra-organisational shock taking the form of a natural disaster. The data used in this study comes from first-person accounts of 31 leavers from four organizations that were affected by an ongoing sequence of earthquakes between September 2010 and December 2011. In a departure from methodological tradition of positivist deductive research (Allen, Hancock, Vardaman, \& Mckee, 2014), we utilise interpretive grounded theory methods to develop a typology of leaving, explicating four distinct paths of turnover decision making around a core category identified from the data. 
The distinctive contribution of this paper lies in not only presenting a new typology of leaving but also in specifying how four contextual factors influence an individual's response to a shock and shape subsequent turnover decision making. These factors, (1) pre-shock motivational state; (2) decision difficulty; (3) experienced shock magnitude; and (4) the availability of resources are discussed in detail. The paper concludes with a discussion of managerial implications, limitations of the study and areas of future research.

\section{THEORETICAL BACKGROUND}

Research on voluntary turnover has been directed at understanding what causes a job incumbent to leave paid employment of their own volition, along with the decision-making processes involved. It has remained the subject of considerable research attention for the past 50 years, with well over 1,500 studies addressing the topic from both a conceptual and empirical perspective (Holtom, Mitchell, Lee, \& Eberly, 2008; Hom, Caranikas-Walker, Prussia, \& Griffeth, 1992; Hom, Mitchell, Lee, \& Griffeth, 2012; Steel, 2002; Steel \& Lounsbury, 2009). Much of the extant literature on voluntary turnover derives from early models proposed by March and Simon (1958); Mobley (1977); Mobley, Griffeth, Hand, and Meglino (1979); Steers and Mowday (1981) and Price and Mueller (1981). Inherent in these attitudinal path models are several presuppositions. First, they assume a mostly rational decision process influenced primarily by desirability of movement (as manifest in job dissatisfaction) and ease of movement (seen as a function of the availability of alternatives). Second, they are further premised on the assumption that quitting is largely an individual decision based on the interaction between the individual and their work environment. Third, they construe turnover decisions as a step-by-step sequential process derived primarily from dissatisfaction that progress in a relatively predictable order. Countless studies have sought to validate and build on these early models through the addition of distal antecedents, mediators, 
moderators, and proximal antecedents of turnover (Holtom et al., 2008; Hom et al., 2012). The net result is a large body of empirical support for a somewhat modest relationship between job dissatisfaction, perceived alternatives, turnover intentions, and turnover (Griffeth, Hom, \& Gaertner, 2000). Much of the criterion variance remains unexplained by existing turnover models with most models explaining between $15-20$ per cent of the variance in turnover (Hom \& Griffeth, 2013; Russell, 2013).

The dominance of these early models, together with a seemingly unwavering focus on prediction, has constrained theoretical development in the field, and placed limitations on the ability to understand the nuanced and complex nature of turnover decisions (Allen, Hancock, \& Vardaman, 2013). Lee and Mitchell's (1994) 'Unfolding Model' represented a refreshing departure from the above research paradigm. Drawing on image theory they argued that leavers follow varied turnover paths, several of which are initiated by a 'shock' and subsequent image violation. Numerous studies provide support for the basic tenets and paths of the unfolding model (Donnelly \& Quirin, 2006; Holtom et al., 2008; Kulik, Treuren, \& Bordia, 2012; Lee, Mitchell, Holtom, McDaniel, \& Hill, 1999; Morrell, Loan-Clarke, Arnold, \& Wilkinson, 2008), while several others have been less confirmatory (Holt, Rehg, Lin, \& Miller, 2007; Morrell et al., 2008; Niederman, Sumner, \& Maertz, 2007), thereby leaving scope for additional inquiry. There is no disputing the fact that the addition of shocks as key 'drivers' of turnover has advanced our understanding of turnover decision-making considerably. Indeed, Holtom, Mitchell, Lee, and Inderrieden (2005) demonstrated that shocks trigger voluntary departures more often than accumulated job dissatisfaction; however, the actual causal mechanisms by which shocks lead to turnover remain understudied. Part of the reason for this lies in the way in which shocks have been defined to date. Shocks are typically construed as a static and oneoff jarring event experienced by an individual, and often unique to the individual. This definition is overly restrictive and does not consider the dynamic nature of shocks; the 
cumulative impact of multiple shocks; or the impact of a significant extra-organisational shock that is commonly experienced employees and other constituents, all of which are characteristic of a post-crisis context. The possibility that a commonly experienced shock, such as a natural disaster, may impact different individuals in varied ways or be perceived by the same individual differently at different times has yet to be explored fully by turnover scholars.

Additionally, shocks have commonly been defined as the 'initiating mechanism' engendering the turnover decision-making process. Holtom et al. $(2005$, p. 341$)$ go as far as to state that unless an event leads directly to job-related deliberations that involve leaving, it should not be considered a shock. As a result very few studies have sought to examine the level of influence "initial shocks" exert on the actual final decision to leave (Kulik et al., 2012; Morrell, Loan-Clarke, \& Wilkinson, 2004). As Morrell et al. (2004, p. 166) note, most studies incorporating shocks fail to acknowledge that an initial shock does not necessarily have to directly influence the final decision to leave. It is, for example, quite plausible that a single shock could initiate a process of decision making, but, on its own be insufficient in prompting leaving. Additional shocks, or a set of circumstances experienced after the initial shock, may be what ultimately results in leaving (Bergman, Payne, \& Boswell, 2012). Such reasoning does not negate, however, the impact of the original shock as a salient part of the decision sequence, albeit somewhat distal from the actual decision to leave. Rather, it suggests there are temporal, contextual, and processual differences in the way in which shocks might lead to turnover. Studies exploring such possibilities are, however, not prevalent in the turnover literature and the interplay between initial shocks, subsequent shocks and actual reasons for leaving has not been adequately studied.

The above limitations are further compounded by methodological shortcomings and the presence of a dominant quantitative analytic mindset amongst turnover scholars that prioritises prediction, parsimony, and generality (Allen et al., 2014). The crux of the argument for those 
who have challenged this mindset is that turnover decisions are human enactments, the complexity of which cannot be captured by cross-sectional or static cohort designs utilising survey measures of independent variables (Morrell \& Arnold, 2007; Steel, 2002). They argue that extant turnover research relies on a level of abstraction that bypasses the ontological, dynamic, and social complexity inherent in turnover decision making (Morrell \& Arnold, 2007). An over-reliance on closed item scale measures of 'stable constructs' has limited the ability to understand how turnover decisions are socially constructed and contextually influenced. Even where attempts have been made to obtain qualitative data from actual leavers, most studies have employed highly structured and deductive research designs utilising strict interview protocols or structured questionnaires [see for example (B. C. Holtom et al., 2012; B. C. Holtom \& Inderrieden, 2006; Jones, Ross, \& Sertyesilisik, 2010; Kulik et al., 2012; T. W. Lee, Mitchell, Holtom, et al., 1999; Morrell \& Arnold, 2007; Niederman et al., 2007; Shipp, Furst-Holloway, Harris, \& Rosen, 2013)]. In such studies the focus is on establishing the presence or absence of an existing theoretical construct, such as a shock. Very seldom are leavers asked to describe in detail their full decision making process (see Donnelly and Quirin (2006) for an exception), or explicate exactly how the experienced shock motivated leaving. Actual shock impact, frequency, and/or cumulative impacts of shock(s) has thus largely been ignored.

The research presented in this paper sought to address these gaps in the literature by exploring turnover decision making in the context of a significant extra-organisational shock following a major natural disaster. This setting provides a unique context within which to study turnover as it is characterised by a significant initial shock followed by numerous subsequent shocks, a high level of disruption to the status quo, and sustained uncertainty. 


\section{METHODOLOGY}

\section{Study context}

The city of Christchurch in New Zealand was hit by a major earthquake in 2010 followed by significant aftershocks in the following three years. Of these, the February 2011 aftershock was the most devastating, resulting in 185 deaths and causing large scale damage to property and infrastructure. Within the first week after the February 2011 earthquake, approximately 55,000 residents left the city, although the majority of these returned following a short period away. Longer term estimates indicate that the population of Christchurch decreased by approximately 3.5 per cent or 13,500 people in the two years from June 2010 to June 2012 (Canterbury Earthquake Recovery Authority, 2014). Unlike many earthquakes, which have a significant initial quake and then a short period of aftershocks, the Christchurch aftershock sequence continued for several years and included numerous significant earthquakes. By mid2014 the region had experienced over 13,000 aftershocks, 55 of these over magnitude 5 and 496 above magnitude 4 on the Richter Scale ${ }^{1}$.

This sustained disruption to businesses and households had a significant impact on employment levels in the region. A 2011 study by the then Department of Labour indicated that of the 1,750 employers interviewed, 28 per cent had experienced difficulties in retaining employees due to the earthquakes (Department of Labour [DoL], 2011). This figure rose to nearly 50 per cent for larger organisations (those employing 50 or more employees). Figures from the Inland Revenue Department (IRD) for the period following the February 2011 earthquake showed that more than 1,000 employees left the region each month for six consecutive months. The extent to which these departures were solely voluntary cannot be discerned from the IRD data and there is no publicly available information on voluntary

\footnotetext{
${ }^{1}$ The Richter magnitude scale is a 10-point logarithmic scale used to assign a magnitude number to quantify the energy released by an earthquake.
} 
turnover rates for the period following the earthquakes. Anecdotal evidence suggests, however, that for several large employers in the region voluntary turnover rates increased significantly in the first two years following the earthquakes.

The post-disaster context of this research also had implications for the timing, design and parameters of the study, in which the researchers were themselves affected by the disaster.

\section{Methods}

Research participants and data collection process

Grounded theory methodology (GTM) was adopted for this study (Charmaz, 2014; Corbin \& Strauss, 2008), in response to calls for more qualitative and in-depth studies of turnover (Allen, Bryant, \& Vardaman, 2010; Hom et al., 2012; Maertz \& Campion, 1998; Morrell \& Arnold, 2007). The research aims and context necessitated collecting data retrospectively, an approach which is uncommon in turnover studies but not uncommon in disaster-related research (Norris et al., 2002; Norris \& Kaniasty, 1992). Additionally, the decision was taken to delay initial data collection until 18 months following the first earthquake in order to account for the cumulative impact of multiple shocks and stressors. Doing so raised some concern relating to memory decay, post-hoc rationalisation and retrospective bias (Lee, 1996; Maertz \& Campion, 2004). These concerns were attenuated by several studies which demonstrated that delayed self-reports of traumatic events showed remarkable stability and reliability over time (Krinsley, Gallagher, Weathers, Kutter, \& Kaloupek, 2003; Lee et al., 1999; Norris \& Kaniasty, 1992).

Four large organisations in Christchurch were approached and requested to assist with the study by identifying all employees who had voluntarily left their jobs in the study timeframe and then forward to them an invitation to participate in the study. The invitation requested that participants contact the researcher directly if they wished to participate in the study. The initial 
response to participate in the study was very positive. Given this positive response, a decision was taken to cluster data collection in sets of three to four interviews, interspersed with data analysis. This allowed for the interview protocol and questions to be adapted to incorporate emergent themes following each cluster of interviews, thereby ensuring that data collection and additional selection of participants proceeded on theoretical grounds. The size of the final research sample was therefore not determined a priori, but rather guided by the GTM tenets of theoretical sampling and saturation (Charmaz, 2014).

To be included in the study participants had to meet three criteria. They had to (a) be in paid employment at the time of the September 2010 earthquake; (b) have experienced the September 2010 and/or February 2011 earthquakes; and, (c) have left their jobs of their own volition in the 18 months following the initial earthquake. 31 people participated formally in the study; a sample size quite typical for GTM studies (Mason, 2010). Participants included 19 females and 13 males, ranging in age from 22 to 57 years. Turnover studies typically rely on single cohort samples and thus research participants are generally quite homogenous. This was not the case in the present study with participants demonstrating significant diversity in terms of tenure, job title, seniority, marital status, and destination following exit.

Primary data were collected through in-depth interviews. Given the nature of the study not all interviews were able to take place face to face, as some participants had left the region or New Zealand altogether. These interviews were conducted over telephone or via video conference using Skype. Of the 31 interviews conducted, 18 took place face-to-face, 6 took place telephonically/via Skype with people living in New Zealand but outside of Christchurch, and 7 took place telephonically/via Skype with people who lived outside of New Zealand. Interview duration ranged from $30-69$ minutes, with the average interview lasting approximately 45 minutes. All interviews were conducted by the first author, recorded, and transcribed verbatim, resulting in 518 pages of typed transcript for analysis. Individual 
transcripts were returned to participants for member checking and verification prior to commencing data analysis.

\section{Data analysis}

Data analysis proceeded through three stages of coding (Charmaz, 2014; Corbin \& Strauss, 2008; Saldana, 2009): Open coding (exploring, conceptualising, categorising and comparing data); focused and axial coding (reassembling data around key categories in order to determine the nature of the relationships between and within categories); and selective or theoretical coding (identifying and describing the central phenomenon in the data). Following a grounded theory process of theory building, all new data were compared with emergent concepts utilizing the constant comparison method and memoing. This process continued until all concepts were fully developed and the relationship between the concepts fully specified. Although the presentation that follows depicts the analytical process as linear, moving from one form of coding to the next, several steps in the analysis took place concurrently or iteratively.

Open coding of interviews commenced as soon as possible after their transcription. This allowed the interview protocol to be adapted to emerging concepts, thereby guiding subsequent data collection. Working inductively, each individual transcript was subjected to rigorous lineby-line coding in order to scrutinise the meaning or essence of the data and identify concepts from the raw data. Open coding generated in excess of 140 substantive codes. Constant comparison served, not only as a means to elaborate the analysis, but also to reduce the number of initial codes by comparing concepts to identify common features or themes among them. Codes that shared similar features or related to the same phenomenon were clustered together under tentative first-order categories (Charmaz, 2014; Corbin \& Strauss, 2008; Saldana, 2012). These higher-level, more abstract, categories crosscut interviews and subsumed several first- 
order codes. In the following sections, words or phrases in italics indicate codes or higher-order constructs.

Focused coding was used to reassemble the data in a coherent way through categorisation and establishing the links between categories and sub-categories. Codes which provided the most incisive conceptual handle on the data were elevated to the level of firstorder category (Charmaz, 2014). An example of such coding is illustrated using the code experiencing latent disquiet. For some time we struggled to make conceptual sense of participants' expressions of restlessness, uneasiness, a subtle nagging and back of the mind thoughts. What many participants seemed to be describing was not active job dissatisfaction or thoughts of quitting, as typically described in the turnover literature, but rather a sense of unease that all was not right with regards to their career trajectory or fit within the organisation. Many described occasional feelings of underutilisation of self or an unanswered callings. Unlike traditional job dissatisfaction, these feelings of disquiet were described as fleeting or back of the mind thoughts. As such, they were seldom subjected to much conscious deliberation or acted upon, hence the code experiencing latent disquiet. This higher-order and more abstract category enabled data reduction and served to raise new questions of the data, thus directing and advancing the analysis in a particular direction. For example, we began to question how latent disquiet influences one's decision to leave. How is latent disquiet surfaced and resolved? What role do shocks play, if any, in surfacing latent disquiet? Such questions were explored in subsequent interviews and data analysis, as well as retrospectively by recoding the transcripts from earlier interviews more thematically using this focused codes. Focused coding resulted in several higher order categories being identified which appeared to hold a place of importance and centrality in the emerging theoretical scheme. These were pursued analytically in order to understand the nature of the relationships between the categories, as well as to elaborate on the properties and dimensions of each. 
The final data analysis stage of selective coding entailed the identification of a core category (Charmaz, 2014; Corbin \& Strauss, 2008). All substantive categories were related to this core category through a set of relational statements.

\section{FINDINGS}

Turnover decision making, as explained by those enacting the decision, is by no means homogenous. The findings reveal considerable variation in terms of the cognitive steps involved and the extent of conscious deliberation afforded to the decision to leave. Our analysis showed the most salient of these differences to be the presence or absence of engaging in critical reflection. Critical reflection was described by participants as a process of conscious deliberation and deep reflection aimed, not at identifying or evaluating alternative employment opportunities, but at interrogating the very assumptions upon which their attachment to the preshock status quo was premised. Initial open coding revealed a variety of approaches used by participants during this process of reflection which included pausing to think seriously about the future; questioning taken for granted assumptions; analysing assumptions and presuppositions; debating and questioning the importance of work or life plans; searching for meaning; re-imagining the future; and reassessing attachment. The concept of critical reflection is illustrated by Aubrey and Harriette's comments:

So then I started to think about all the other things like you know, understanding where I was in my life or where I thought I was in my life. And then, after a week or two weeks, I started to think to myself, "Well, look if this is going to have marked effect on how I do things with my life, where is my life? Is everything in order?” My marriage is good, click, ticked. Family's fine. Phone, house, got a job. The future, hmmm? I sat down with my wife and she said to me "Well, to what do you isolate the main problem?" 
And that's basically how it [the process of critical reflection] started. (Aubrey, Male, 52)

So I had what I wanted [in terms of career] and then, yeah, just change [the earthquakes] came along and, yeah, made me think about my own future in different terms. It caused me to question the things that I had taken for granted. That, you know, your home that you thought you were going to spend the next number of years in is perhaps not as important as you thought it was going to be. Decisions about the future of your city are changed therefore the job that you thought you were always going to have maybe you aren't always going to have it and maybe you shouldn't always have it and maybe it's time to seize a new opportunity and make changes. (Harriette, Female 54)

The analysis found that engaging in critical reflection, most commonly centred on attachment to people, place or profession. Given its importance in the analysis, engaging in critical reflection was elevated to the level of core category, and all substantive categories were related to this core category. Doing so led to the emergence of four distinct patterns of leaving which are labelled: (1) Deliberate departers; (2) New beginnings; (3) Reluctant departers; and, (4) Tragic endings. In the section that follows each type of leaving is discussed in detail.

\section{Deliberate departers $(n=8)$}

Deliberate departers held a strong pre-shock preference for leaving which was manifest in thoughts of quitting, strong intentions to leave, active job search behaviour and previous attempts at securing alternative employment. Leaving was viewed as a means to address active job dissatisfaction or enact pre-existing plans for leaving. Deliberate departers thus displayed high psychological readiness to leave. However, their ability to enact this preference for leaving was constrained by exogenous circumstances, most commonly a lack of suitable alternative 
employment opportunities. Deliberate departers perceived low volitional control over the ability to leave and experienced frustration at not being able to leave as explained by Alec below:

There was [sic] a lot of things I wasn't satisfied with, for instance the job roles and the people I was with.... and it was always if the perfect job role came up I would have jumped at the chance... I was always looking but you've got to get the right role... I always had the plan [to make a career switch into teaching] there... It's been like 12 years now, this whole plan's been in the making... But I knew that I had to look after myself financially, and even mentally... But I also knew I couldn't stay down the bottom for my own sanity as well. (Alec, Male, 34)

The shock(s) appeared to have minimal direct impact on the decision making of deliberate departers and was seldom attributed as the primary reason for their leaving. Rather, the shock(s) acted as an effectuation mechanism by removing barriers to, or enhancing opportunities for, leaving; thereby increasing volitional control over the existing preference to leave, as Alec goes on to explain:

I never actually had a definite point when I was going to leave, it was always a, "When a teaching position comes up for teaching aiding, or a role that works with kids came up that was when I was going to go"... and so after the quakes, funding came through the Ministry [of Education] for more teacher aides to go into schools, and then that gave me a role into a school. (Alec, Male, 34)

The shock(s) played an additional secondary role by eroding community embeddedness and attachment to place, which in turn expedited the enactment of pre-existing plans for leaving or reduced decision strain associated with accepting unsolicited job offers. 
Deliberate departers had weak, if any, attachment to the pre-shock status quo, thus their decision to leave did not entail a transitioning of motivational state or require psychologically detaching from the status quo. There was thus little, if any, need to engage in a process of critical reflection. Decision making centred on leaving one organisation for another, with utility maximisation being the key consideration. Active job search behaviour and a rational evaluation of known alternatives played a central role in the decision making of deliberate departers, and securing suitable alternative employment was most often deemed a prerequisite for leaving. The analysis suggest that for deliberate departers once barriers to leaving are removed and a job offer is in hand, enacting the decision to leave is rapid and takes place with little decision or emotional strain. This process is depicted in Figure 1.

Insert Figure 1 about here.

Most deliberate departers viewed leaving as a positive outcome and a means to advance their career or pursue more meaningful vocational interests. Leaving typically resulted in an upward, or at least lateral, career move. These leavers were typically quite happy to part ways with the organisation, given that their primary reasons for leaving stemmed from dissatisfaction with the status quo, and in particular dissatisfaction with the job.

\section{New beginnings $(n=9)$}

Although generally satisfied with, and committed to, their jobs prior to the shock(s), people in this category described an underlying sense that they would not stay with the organisation forever. Exactly when or how they might leave was, however, undefined. Future plans for leaving, if they existed, were vague or indeterminate as little conscious deliberation had been afforded to latent disquiet and intermittent thoughts of leaving (e.g. one day pursuing an unanswered vocational calling). Unlike deliberate departers, any pre-shock preference for 
leaving was weak (or dormant) and had yet to manifest in definitive quit intentions or active job search behaviour. While these individuals perceived relatively high volitional control over staying or leaving, they had yet to develop a clear preference for leaving prior to the shock(s).

The shock(s) had a direct impact on their decision to leave and served to initiate the decision making process by disrupting the status quo and surfacing latent disquiet, which participants experienced as unsettling. This surfacing of latent disquiet is illustrated by Aubrey and Leona:

I guess in a way it's like the anecdote. You put a frog in a saucepan of water and you heat it and the frog don't do nothing, but you drop the frog into hot water and it does everything in its power..... I could have stayed at [the organisation]. I suspect strongly if nothing had happened like it did I might well have stayed, because..... I don't know. Because something did happen.... I knew when I went into town that day [as part of an urban search and rescue first response team] everything changed - changed everybody's life around me and I knew I couldn't escape those "I need to do something's." (Aubrey, Male, 52)

So it was sort of like well, I might as well do this [pursuit of a more meaningful role/ an unanswered calling] now and just get on with this because that whole thing about life is too short... So if we are not doing what we love then it does feel like, what is the point? (Leona, Female, 33).

The shock(s) may also played a secondary, and more indirect, role in the decision process by introducing a period of hiatus, during which latent disquiet was surfaced and critical reflection took place, as Lydia explains:

...I had that time off that - those two months, and even though I was enjoying myself it did become very clear - I was [long pause] I was [pause] I felt myself change a 
lot....and when you distance yourself from the things that have affected you so very much, the things that you've neglected I guess over a period of time or, things you've neglected to think about or to give attention to become very - what's the word - they kind of "flood" you. (Lydia, Female 22)

For these individuals, turnover deliberations were generally triggered by the initial jarring impact of the shock, while the sustained and cumulative impact of subsequent shocks played a less significant role. The surfacing latent disquiet generated cognitive dissonance which the individual attended to by engaging in critical reflection. Critical reflection most commonly centred on conflicting preferences for staying and strengthening pull forces for leaving. Critical reflection led to a realisation that leaving represented a desirable outcome and an opportunity to make a new and positive start. Participants often likened this coming to a realisation to an epiphany or serendipitous moment of clarity that enabled them to transition from a staying mindset to one of leaving, as this comment by Colby illustrates:

And it was quite euphoric at the time because it made, you know, it was almost like having an epiphany if you like, you know, "Oh, no, hang on, we can actually do this [leave to start his own business]. It was like I got a "eureka" moment, a sort of feeling that we could really do it, you know. It was liberating." (Colby, Male 50).

Psychologically detachment from the pre-shock status quo was followed quite shortly by the crystallisation of a decision to leave. As the decision to leave often centred on the pursuit of more meaningful opportunities (often unrelated to the current role or career), securing alternative employment was not always a prerequisite for decision enactment. Job search activity or a rational weighing of alternatives generally only occurred after the decision to leave had crystallised, as depicted in Figure 2. 
Insert Figure 2 about here.

Individuals described their decision to leave as a positive opportunity to pursue more meaningful work or relationships that they otherwise may have been reluctant to pursue prior to the shock. Their departure often involved more than just moving from one organisation to another for a similar position, and included occupational changes, a move into selfemployment, and exiting the formal labour market altogether. Individuals in this category reported feeling sadness at leaving the organisation, but at the same time were highly optimistic about the future.

\section{Reluctant departers $(n=8)$}

Reluctant departers exhibited low pre-shock psychological readiness to leave due to their contentment with, and strong attachment to, the pre-shock status quo. They exhibited a high level of job satisfaction, affective commitment and embeddedness, and had clear plans to stay with their organisation. Reluctant departers perceived a high level of volitional control over this staying preference, as illustrated by Harriette and Brenda:

I had what I considered to be the dream job, the job I had always wanted at [the company], I had it....I would say that the whole earthquake situation and the work ramifications of that were sufficiently destabilising to prompt me to think about a change that I probably wouldn't have considered before. (Harriette, Female 54).

And just an amazing team, I just couldn't have asked for better. I haven't actually ever worked anywhere where I have had a better team structure, better team values, and principles. There was [sic] never any issues. (Brenda, Female 48) 
This pre-shock motivational state appeared to buffer reluctant departers against the jarring impact of the initial shock. However, the cumulative impacts of multiple shocks diminished participants' perceived control over their preference to stay to a point where they felt compulsion to leave. Sustained exposure to stressors arising from the altered social context ultimately resulted in a tipping point being reached, as Barry and Colby explain:

I think we started really to feel bit more positive about it, then there was a bad earthquake in April and then there were obviously lots of earthquakes, but those ones in July were pretty grim.... my partner pretty much burnt out... then July came along and we just sort of folded really, you know. (Barry, Male 35)

I started trying to project manage [a house build] as well as work and I got to September and I said, "I can't do this anymore, I'm about to have a breakdown" sort of thing, you know. (Colby, Male 50)

This forced participants to reconsider their attachment to the status quo. Most reluctant departers were able to self-impose a period of hiatus during with they engaged in critical reflection, often with the support of significant others. Critical reflection centred on resolving dissonance stemming from tension between a strong preference to stay and strengthening push forces for leaving. Critical reflection led to a realisation that leaving represented the most appropriate outcome for dealing with the circumstance faced. This acceptance enabled participants to psychologically detach from the status quo, which was followed shortly by the crystallisation of a decision to leave. Securing alternative employment was generally not the primary focus of the decision and thus not viewed as a prerequisite for decision enactment. Job search activity and a rational weighing of alternative opportunities seldom featured as part of the decision making process, as depicted in Figure 3. 
Insert Figure 3 about here.

While reluctant departers recognised that leaving was in their best interests, they did so reluctantly. As a result of having to psychologically detach from the pre-shock status quo the decision process was cognitively and emotionally straining. Despite this, decision outcomes were generally described as positive and most reluctant departers went on to gainful employment in similar positions or industries with the aim of keeping their pre-shock career or life plans on track.

\section{Tragic endings $(n=6)$}

Similar to reluctant departers, tragic endings held a strong pre-shock preference for staying and perceived high volitional control over this preference. They reported high levels of pre-shock job satisfaction, embeddedness and affective commitment towards the organisation. They anticipated staying with the organisation for the long term and had not entertained any thoughts of quitting, as illustrated by Estelle:

I had a continuous employment history of about 38 years... I had been at that particular office for exactly 20 years to the day of the earthquake. It [leaving] wasn't on the agenda in the slightest, I mean, I loved my job. I absolutely loved it because I got to meet all these interesting people from all around the world. (Estelle, Female 57).

Tragic endings exhibited both low pre- and post-shock psychological readiness to leave due to their contentment with, and very strong attachment to, the pre-shock status quo. As with reluctant departers, this state of contentment was challenged by cumulative stressors arising from the altered social context. Tragic endings made repeated unsuccessful attempts at 
maintaining or restoring the pre-shock status quo, until a point was reached where they could no longer cope with the situation as Wendy explains:

And the situation in my family was going from bad to worse since the earthquakes. My parent's home was damaged and we had to sort of dig the house out... it was like the whole of Christchurch was in chaos. And then on top of this my father was diagnosed with dementia, which of course, sort of was [long pause] I think everybody had got so stressed that every sort of weak link just broke... it was just too much and one day I just felt like - you know I just couldn’t carry on any more. I was sort of thinking that that's it. I just can't do it [cope] anymore. (Wendy, Female 51).

Unlike reluctant departers, who were able to recognise the reaching of a tipping point, significant escalating demands and significantly diminished resources impaired the ability of tragic endings to recognise the reaching of a tipping point. Instead, these participants became overwhelmed by the demands placed on them by the altered social context, and in response to a last straw shock, made an impulsive and emotionally-charged decision to quit. In most cases the decision to quit and its enactment occurred within a short space of time of one another, even simultaneously, as is illustrated by Brenda:

So she [manager] came in and she said that she didn't want those pieces of paper up there [on a notice board] like she'd previously told me... and it wasn't the worst thing she'd ever said, but it was the final straw...I breathed a bit and then adrenalin just flooded me with indignation and I just thought a few choice words. I went downstairs found an office that was empty, opened up my email, and typed out my resignation letter. I was absolutely shaking with adrenalin. I went to [the operations manager] and I handed it [resignation letter] to him, which I had signed, and he read it and he said “do you want to talk?” and I so said “no, I don't want to talk, I'm just going to pack up 
my stuff, I'm going to pack up everything that I can right now and I'll be gone, I'll come back and get the rest of it later". He [the operations manager] thought it [the situation] was all right. The only reason he thought it was all right is because I was working so bloody hard to make it look like it was working... so it broke my heart. It totally broke my heart. I had waited a year for my job, to do what I love and do well and give back to the [specific] community again and it was stolen from me basically. (Brenda, Female, 48)

Job search behaviour and a rational choice between alternatives did not feature at all as part of the decision process for tragic endings, and securing alternative employment was not deemed a prerequisite for leaving. Several key features distinguish tragic endings from reluctant departers. These include a failure to recognise the reaching of a tipping point; greater severity of resource deterioration; the presence of a last straw shock; and the absence of hiatus and critical reflection. Resoluteness to maintain or restore the pre-shock status quo meant that tragic endings afforded little, if any, conscious deliberation to leaving. Faced with significantly depleted resources and ongoing demands, the decision to leave appeared not to be the outcome of a process of reasoned decision making, but rather an impulsive response to an acute stressor, as depicted in Figure 4.

Insert Figure 4 about here.

Tragic endings did not want to leave their organisation. They would have preferred to stay and 'go back to things the way they were prior to the shock'. Failure to engage in critical reflection and psychologically detach from the status quo resulted in a high degree of cognitive 
and emotional strain, which appeared to impact the ability of the individual to successfully consider alternatives and subsequently transition into a new role.

I didn't feel good about it, but it was sink or swim for me and I said to [the operational manager], nobody else is going to do this for me. Nobody is there for me. Nobody else has stood up for me. I'm the only one that can do this and I have to do this and I have to do it today. (Brenda, Female, 48)

As Raquel's comment below illustrates, tragic endings seldom exited with a job offer in hand, and commonly reported engaging in post-hoc critical reflection in attempt to make sense of, and come to terms with, their decision to leave:

So I did hand in my resignation. I took a couple of weeks off with sick leave, because I had so much sick leave owing and I was just so stressed out. And then I was like "oh my God what do I do now". Yeah, up until then it was just reactionary. It was when I left, that all of a sudden I could sit back and have time to reflect on what I was good at and what I really wanted to do with my life. And that's when I started my own baking business. Low and behold that's actually going like the clappers and I love it. (Raquel, Female, 48)

Four of the six participants in this group reported engaging in post-decision critical reflection that resulted in quite dramatic career or job shifts, or leaving the workforce altogether. Negative case analysis revealed one participant, Doris (female, 52) who at the time of the interview, explained that she had still not had the opportunity to fully recuperate and step back from her situation in order to reflect and engage in conscious deliberation about the future. This she attributed to an inadequacy of physical, psychological and time resources for doing so, as well as a lack of social support. She remained in 'response mode' and while she had been successful in 'escaping' her immediate physical situation, she had yet to psychologically detach 
from the pre-shock status quo, which in turn inhibited her ability to transition to a new life outside of the disaster area.

Doris' account, as well as those of the other five participants in this group, highlight the important role of engaging in critical reflection and detaching from the status quo in turnover decision making. The analysis revealed that failure to engage in critical reflection and detach from the status quo hinders one's ability to undertake a more rational consideration of alternatives, which in turn can result in detrimental consequences for the individual. From a career or employment perspective, tragic endings all viewed the outcome of their decision to leave negatively.

\section{DISCUSSION}

The typology of leaving highlights the heterogeneous nature of turnover decision making and reveals the process to be significantly more complex than that suggested by traditional affect-driven models of voluntary turnover. The four paths to leaving vary considerably in terms of the nature and intensity of conscious deliberation afforded to the decision to leave. For tragic endings, the final decision to quit is impulsive and involves little in the way of conscious deliberation or rational decision making. Deliberate departers exhibit a more moderate level of conscious deliberation but do not engage in a process of critical reflection, as a relatively straight forward and rational choice between known alternatives suffices as the core decision process. The decision paths followed by new beginnings and reluctant departures involve extensive deliberation, coming in the form of the complex, and often emotionally-laden process of engaging in critical reflection. We account for this variation by specifying how four contextual factors shape turnover decision making. These factors, (1)

pre-shock motivational state; (2) decision difficulty; (3) experienced shock magnitude; and (4) 
the availability of resources are discussed in detail in terms of the unique contribution they make to extant turnover theory and their relationship to previous research.

\section{Pre-shock motivational state}

Pre-shock motivational state captures the broad staying or leaving mindset embodied by an individual prior to experiencing a shock. By conceptualising three distinct pre-shock motivational states, we are able to explain instances of turnover that are not derived from job dissatisfaction or strong intentions to quit, thereby addressing a significant gap in the extant turnover literature. The findings indicate that employees who already experience discontent with the status quo are less likely to engage in critical reflection than those who experience disquiet with the status quo or are content with the status quo. This finding lends support to the arguments proffered by Maertz and Campion (2004), and more recently Hom et al. (2012), that different pre-departure states are likely to result in alternative forms of decision framing and sequencing.

Being content with the status quo corresponds closely with Hom et al.'s (2012) 'enthusiastic stayer' mindset, which is characterised by a high degree of affective commitment and person-job fit. Hom et al. (2012, p. 840) posit that employees likely to "stay with an organisation until they retire, become disabled, die or spontaneously receive better job offers". The findings of the present study do not support this assertion, demonstrating instead that the shocks have the potential to result in an individual transitioning from a very strong staying mindset to one of leaving. While such transitioning of motivational state is alluded in the literature, the process by which this might occur has yet to be articulated by researchers (Bergman et al., 2012). The findings of the present study address this gap directly by highlighting the complex interplay between shocks and pre-shock motivational state, and explicating how engaging in a process of critical reflection facilitates the transitioning of 
motivational state. Our findings suggest that when an individual is highly content with the status quo, shocks are less likely to directly alter an existing preference for staying. This finding is consistent with organisational commitment theory which argues that employees with high levels of affective commitment are likely to resist countervailing forces that have potential to disrupt continued employment(Meyer, Becker, \& Vandenberghe, 2004), and recent studies which suggest that job embeddedness buffers shock impacts (Burton, Holtom, Sablynski, Mitchell, \& Lee, 2010). Importantly, however, our findings suggest that there are limitations to the arguments offered by Burton et al. (2010) regarding the buffering effects of job embeddedness. We suggest that the initial buffering effect of pre-shock motivational state is not necessarily sustainable in the context of multiple shocks and sustained disruption to the status quo. Furthermore, our findings run counter to Burton et al.'s (2010) argument that exposure to shocks results in a greater ability to deal with subsequent, and even more significant, shocks. For example, the last straw shocks that led some participants to quit impulsively were often benign and less significant in terms of impact than the initial shock.

Our findings suggest that shocks have a more direct impact on the desirability of leaving when there is pre-existing disquiet with the status quo. Participants whose pre-shock motivational state was characterised as disquiet with the status quo held a weak or dormant preference for leaving, underpinned by latent disquiet. We argue that, by not being actively dissatisfied, these individuals feel little compulsion to act on the underlying disquiet. This argument fits with Hom et al's. (2012, p. 851) assertion that "when affect is relatively neutral and one has control over the decision to stay or leave, the status quo wins - it is easier to stay than leave". Importantly, however, our findings reveal that shocks directly impact this suggested state of 'neutral affect' by surfacing latent disquiet which in turns initiates turnover deliberations. As such our findings are consistent with the traditional conception of shocks as jarring events that directly initiate the psychological processes associated with leaving (Holtom 
et al., 2005). However, our findings extend the current understanding of how shocks trigger turnover deliberations by elucidating the new construct of latent disquiet and explicating the role of shocks in surfacing disquiet and strengthening dormant preferences for leaving.

\section{Decision difficulty}

Decision difficulty captures the magnitude and complexity of the decision to leave, and is conceptualised by integrating the three categories of decision locus, decision control, and decision magnitude. Our findings reveal that turnover decision vary according to degree of difficulty and range from a relatively straight-forward choice between known alternatives to more complex decisions involving unknown alternatives, significant uncertainty and a high degree of psychological strain. The findings indicate that decision difficulty is highest when there is a collective decision locus, when decision magnitude is high, and when the individual perceives low volitional control over their decision. We argue that decision difficulty directly influences the extent of conscious deliberation afforded to the decision to leave, such that the need to engage in critical reflection increases in accordance with increasing decision difficulty. This argument is consistent with research in the field of judgement and decision making, which suggests that complex and multidimensional decisions involving high levels of uncertainty and the substantial investment of resources necessitate subjecting the decision to significant levels of conscious deliberation (Broniarczyk \& Griffin, 2014; Calvillo \& Penaloza, 2009; Chatterjee \& Heath, 1996; Dijksterhuis, Bos, Nordgren, \& Van Baaren, 2006).

\section{Experienced shock magnitude}

A third factor to influence the nature of turnover decision making is the degree to which a shock disrupts the pre-shock status quo and destabilises the individual. This disruptive impact is conceptualised as experienced shock magnitude. It is derived from two categories: perceived 
shock impact and perceived event continuity. Perceived shock impact captures the direct consequences of a shock(s) and the disruptive impacts of the resulting altered the social context as subjectively experienced by participants. Perceived event continuity refers to the duration of perceived shock impact; more specifically, whether an individual is affected by the initial jarring impact of the primary shock or the more cumulative and sustained impact of multiple shocks and stressors in the altered social context.

The findings indicate that when shock impact is low a single shock is unlikely to trigger turnover deliberations. This is consistent with Lee and Mitchell's (1994) argument that shocks need to be sufficiently jarring in order to shake an individual from his or her inertial state. Also consistent with Lee and Mitchell's view on shocks, the findings suggest that when shock impact is high, discrete events can lead directly to turnover deliberations. However, our findings suggest that that this occurs most often in the presence of latent disquiet or when positive affect is low. When positive affect is high and attachment to the pre-shock status quo strong, discrete shocks are much less likely to directly prompt turnover deliberations; even when shock impact is high. We observed, however, that sustained exposure to stressors eroded the ability of an individual to withstand subsequent shocks. These limits were evidenced in cases where participants, who had long withstood the impact of the initial shock, ultimately reached a tipping point where they felt compulsion to reassess their attachment to the status quo; or worse made an impulsive decision to leave in response to a last straw shock. This suggests that in order to destabilise an individual who is highly content with the status quo, experienced shock magnitude must be high; that is both shock impact and event continuity need to be high. These findings are consistent with conservation of resources (COR) theory (Hobfoll, 1989; Hobfoll \& Freedy, 1993) that argues that resource loss is more salient than resource gain, and that the sustained loss of resources is likely to result in stress, burnout, emotional exhaustion, depression, and physiological strain (Halbesleben, Neveu, Paustian-Underdahl, \& Westman, 
2014). We found that when shocks threatened an individual's attachment to the pre-shock status quo they invested significant resources in attempts to maintain or restore the status quo. While such resources were initially abundant, the cumulative impacts of the altered social context had a direct influence their availability. The sustained nature of the unique aftershock sequence meant that participants had little opportunity to replenish resources in the face of escalating demands. We argue that this resulted in participants entering a spiral of resource loss, which diminished their resilience to withstand subsequent shocks. Hobfoll (2011) notes that resource loss spirals are particularly common following significantly traumatic or stressful events. This is understandable given that natural disasters threaten a host of object (housing); personal (optimism, safety); social (kinship and friendship ties); and energy (time, money) resources (Norris, Stevens, Pfefferbaum, Wyche, \& Pfefferbaum, 2008).

By explicating the interplay between experienced shock magnitude and pre-shock motivational state, this paper offers an explanation as to why not all shocks result in leaving; and, significantly, how the cumulative exposure to multiple shocks might erode personal resilience and render an individual more susceptible to subsequent shocks. This addresses a significant gap in the turnover literate where shocks have typically been defined as discrete events that lead directly to turnover deliberations (Holtom, Burton, \& Crossley, 2012; Holtom et al., 2005). As a result of this very narrow definition of shocks, researchers have most often tended focus on 'the shock' and not the actual disruptive impacts of the shock or the cumulative effect of multiple shocks, despite acknowledgment in the literature that "more shocks is worse" (Purl, Hall, \& Griffeth, 2016, p. 224). Based on the above findings we argue that construing shocks as a single distinguishable event that jars an employee toward deliberate judgments about his/her job is overly simplistic (Holtom et al., 2005). We address this shortcoming directly by explicating the complex relationship exists between initial, subsequent, and last straw shocks and conceptualising the new construct of experienced shock magnitude. 


\section{Resources: the importance of hiatus and social support}

The preceding section argue that the core decision making process of engaging in critical reflection is necessitated when an individual is (1) content with the status quo, (2) faces with a complex and difficult decision, and (3) experiences moderate to very high shock magnitude. In grounded theory terms, these three factors represent 'causal conditions' as they lead the occurrence of the core category (Corbin \& Strauss, 2008; Kelle, 2007). However, by themselves, they do not fully account for the presence or absence of the core category of engaging in critical reflection. Our analysis revealed that the ability to successfully engage in critical reflection was further influenced by two enabling conditions or resources, namely: (1) hiatus and (2) social support. Our finding indicate that findings clearly indicate that hiatus facilitates engaging in critical reflection by providing the time, respite, physical and mental space necessary to engage in the process. On the other hand, the absence of hiatus, or respite from day-to-day demands, inhibits the ability to successfully engage in critical reflection. This finding is consistent with Mezirow's (1990) assertion that premise reflection cannot be part of the immediate action process but requires hiatus from activity in which to critically assess and transform one's assumptions.

The findings suggest that social support influences engaging in critical reflection in two main ways. First, a partner or significant other can initiate the process of reflection by helping an individual recognise a tipping point has been reached, and encouraging them to 'take a step back' from the situation. Second, social support, appears to play an important role in facilitating the actual process of reflection, particularly when decision locus is collective rather than individual. This was evidenced in the data when participants recalled debating with significant others the assumptions, presuppositions, and beliefs that underpinned their attachment to people, place or profession. In contrast, participants who experienced a significant deterioration, or a lack of social support were seemingly unable to recognise the reaching of tipping point and failed to engage in critical reflection. The findings further suggest that 
deterioration of social support contributed to diminished personal resilience and rendered participants more susceptible to final-straw shocks. Ultimately it was these participants who experienced the most deleterious outcomes of their decision to quit. Within the disaster management literature, the importance of social support as a vital resource for coping in the aftermath of a disaster is well established (Aldrich, 2012; Kaniasty, 2012; Norris et al., 2002). Social support has also been shown to be a key determinant of psychological resilience and one's ability to 'bend, but not break' following a significant event or traumatic disturbance (Bonanno, Galea, Bucciarelli, \& Vlahov, 2007; Sippel, Pietrzak, Charney, Mayes, \& Southwick, 2015). However, the role of social support has received far less attention from turnover researchers. We address this gap directly and argue that the availability of resources moderates the extent to which critical reflection forms part of turnover decision making, such that: (1) both the presence and efficacy of engaging in critical reflection will be greater when an individual experiences hiatus and social support; (2) individuals who experience sustained resource depletion will be less likely to engage in reasoned decision making and more likely to make a spontaneous decision to leave.

\section{Implications for managerial practice}

Our findings have important implications for the management of employee turnover following a significant extra-organisational shock. First, organisational mitigation of turnover is possible in some instances, but not all. Thus post-crisis recovery plans need to prepare for 'unavoidable' employee turnover, while seeking to mitigate 'avoidable' turnover, where possible. Additionally, managers need to be aware that employee turnover is possible throughout the post-crisis life cycle, and not only in the period immediately following a significant shock. In this respect, the findings identify several stages in the decision-making process during which managers may be able to mitigate employee turnover, namely (a) when 
latent disquiet is first surfaced, (b) when a tipping point is reached, (c) when an employee is actively engaged in the process of critical reflection. However, the findings strongly suggest that once a decision to quit has crystallised, organisational mitigation of turnover is highly unlikely. Related to this is the finding that job search and the evaluation of alternatives played a very limited part in many of the participant's decision making, and securing alternative employment was not always a prerequisite for leaving for many a participant. Monitoring of job search behaviour is thus unlikely to be of much benefit to managers seeking to mitigate turnover of such individuals. Similarly, monitoring commonly accepted attitudinal predictors of turnover such as job dissatisfaction or intention to quit may be of less utility in the context of a significant extra-organisational shock, given the finding that many employees who left were highly satisfied with their jobs. Managers would be better advised to monitor employee stress levels following a significant shock. This could be done at an organisational level through the systematic collection of data using survey measures of job strain or burnout, and at an individual level during constructive conversations between line managers and individual employees.

Careful consideration should be given to the timing and nature of organisational support offered to employees. Organisations most often concentrate their efforts to support employees in the period immediately following a significant shock, and then scale these back over time. Our findings suggest that the withdrawal of support could lead employees to reach a tipping point more quickly. Employees who come through the strongest at the start of a crisis may well be at the highest risk of leaving during later stages of the recovery or post-recovery period. Providing employees with the opportunity to recuperate and replenish resources is important in maintaining personal resilience. However, hiatus from regular routine and daily distraction may also provide satisfied employees with the mental space required to surface latent disquiet and reflect critically on their attachment to place, person or profession, which could lead to 
turnover. Managers should thus identify means of keeping employees engaged. Potential strategies may include temporarily relocating employees, putting in place alternative work schedules or allowing employees to work from home (Nilakant, Walker, Rochford, \& Van Heugten, 2013). Where employees are required to work in isolation, managers should attempt to preserve pre-existing social structures and utilise existing social capital to support at risk employees. Managers are also advised to maintain contact, where possible, with employees who self-impose a period of hiatus, as it is during such times that employees are most likely to engage in critical reflection and subsequent turnover deliberations. Doing so requires managers to establish trust-based relationships with their employees (Walker, Nilakant, \& Baird, 2014).

Finally, and more specific to the post-crisis context, managers need to recognise that in seeking to support their employees to cope with the shock, they themselves are at risk of compassion fatigue and vicarious traumatisation (Johal, 2015; Johal, Mounsey, Tuohy, \& Johnston, 2014).

\section{Limitations and directions for future research}

While this grounded theory study offers a rich and nuanced explanation of the turnover decision making process, it is not without its limitations. First, we acknowledge that no study will ever be able to fully for account for, and describe, every contextual influence that might have a bearing on a particular human behaviour or social process being investigated (Johns, 2006). Thus, the four types of leaving identified in this paper may not represent all possible forms of leaving, neither do the four contextual factors identified represent all of the contextual influences that serve to shape the decision making of individuals. Future studies may seek to elaborate the decision paths we propose or specify additional contextual influences which might shape decision making in settings outside of the post-disaster context. 
Second, the findings of this study are limited to the context in which it was conducted. It was never our aim to develop a grand and generalisable theory of turnover, but rather to produce a more nuanced and substantive theory grounded in a post-disaster context. We acknowledge this limitation but argue that the findings of this study may well be generalisable to similar contexts where employees are subjected to a significant and commonly experienced shock and subsequent shocks. Future research could test our proposed typology in similar contexts such as a major financial crisis, industry shake up, or major organisational change initiative.

Third, this study specifically sought to understand the decision making processes associated with leaving, and therefore did not study stayers. Our finding that engaging in critical reflection resulted in individuals transitioning motivational state from a staying to leaving preference may well work in opposite direction. That is, a shock may initiate a process of critical reflection that causes someone with strong preference to leave to develop a strong preference to stay. We acknowledge this limitation and encourage future research to focus on the decision processes associated with both staying and leaving.

Fourth, several limitations with the way in which data was collected warrant discussion. Our data was all collected retrospectively via in-depth interviews. The necessity of this approach has been discussed in earlier sections, however, we must acknowledge the limitations of using self-report retrospective accounts. Future research examining actual turnover decision making could utilise diary-based methods for data collection. Doing so would address much of the concerns regarding retrospective accounts and provide researchers with more fine grained data. Doing so might aid in identifying, for example, exactly when a tipping point is reached or at what point resource deterioration leads to an impulsive decision to quit. Future research should also consider collecting data from all individuals involved in the decision to leave. As 
our findings suggest the actual decision to leave was seldom an individual decision but was taken collectively within a marriage or significant relationship.

Lastly, participation in the study was voluntary. It is thus possible that participants had a common motivation for participating in the study. Indeed some participants explained that they chose to participate in the study in an attempt to make sense of their disaster experience. We were aware of such limitations and thus built reflexivity into the data collection and analysis from the outset. We also acknowledge that having a common shared experience with one's research participants has both its strengths and drawbacks. The fact that both authors were impacted by the Canterbury earthquakes allowed us to build rapport and trust with our research participants. It also introduced the risk of bias, the arousal of strong emotional responses from participants, and the possibility that research may cause distress for the participants as well as for the researchers. We sought to address this limitation by following Corbin and Morse's (2003) protocol for conducting unstructured in-depth interviews.

\section{CONCLUSION}

By departing from methodological tradition we are able to propose a nuanced theory of turnover decision making. We identify several new constructs that explain the causal mechanisms by which shocks may lead to quitting. We also provide evidence of the role of context in shaping turnover decision making, highlighting the important role of pre-shock motivational state, decision difficulty, experienced shock magnitude and the availability of resources. In conclusion our findings emphasise the importance of 'putting things into context' in order to gain a more thorough understanding of what is a very well-researched phenomenon. 
Abrams, A. (2016). It's Not Just Canada: New Zealand Immigration Sites See Spike in U.S. Traffic After Donald Trump Win. Time Magazine. Retrieved from Time.com website: http://time.com/4566657/donald-trump-election-new-zealand-immigrationwebsite/

Aldrich, D. P. (2012). Building resilience: Social capital in post-disaster recovery: University of Chicago Press.

Allen, D. G., Bryant, P. C., \& Vardaman, J. M. (2010). Retaining Talent: Replacing Misconceptions With Evidence-Based Strategies. Academy of Management Perspectives, 24(2), 48-64.

Allen, D. G., Hancock, J. I., \& Vardaman, J. M. (2013). Analytical mindsets in turnover research. Journal of Organizational Behavior.

Allen, D. G., Hancock, J. I., Vardaman, J. M., \& Mckee, D. N. (2014). Analytical mindsets in turnover research. Journal of Organizational Behavior, 35, S61-S86. doi: Doi 10.1002/Job.1912

Berenson, T. (2016). Donald Trump Wins the 2016 Election. Time Magazine. Retrieved from time.com website: http://time.com/4563685/donald-trump-wins/

Bergman, M. E., Payne, S. C., \& Boswell, W. R. (2012). Sometimes Pursuits Don't Pan Out: Anticipated Destinations and Other Caveats: Comment on Hom, Mitchell, Lee, and Griffeth (2012). Psychological Bulletin, 138(5), 865-870. doi: Doi 10.1037/A0028541

Bonanno, G. A., Galea, S., Bucciarelli, A., \& Vlahov, D. (2007). What predicts psychological resilience after disaster? The role of demographics, resources, and life stress. Journal of consulting and clinical psychology, 75(5), 671.

Burton, J. P., Holtom, B. C., Sablynski, C. J., Mitchell, T. R., \& Lee, T. W. (2010). The buffering effects of job embeddedness on negative shocks. Journal of Vocational Behavior, 76(1), 42-51.

Canterbury Earthquake Recovery Authority. (2014). Canterbury Wellbeing Index: Population (pp. 1-13). Christchurch, New Zealand.

Charmaz, K. (2014). Constructing grounded theory: Sage.

Corbin, J. M., \& Morse, J. M. (2003). The unstructured interactive interview: Issues of reciprocity and risks when dealing with sensitive topics. Qualitative Inquiry, 9(3), 335-354.

Corbin, J. M., \& Strauss, A. L. (2008). Basics of qualitative research : techniques and procedures for developing grounded theory (3rd ed.). Los Angeles, Calif.: Sage Publications, Inc.

Department of Labour [DoL]. (2011). A Changing Landscape: The Impact of the Earthquakes on Christchurch Workplaces (pp. 1-28). Wellington, New Zealand.

Donnelly, D. P., \& Quirin, J. J. (2006). An extension of Lee and Mitchell's unfolding model of voluntary turnover. Journal of Organizational Behavior, 27(1), 59-77. doi: Doi 10.1002/Job.367

Griffeth, R. W., Hom, P. W., \& Gaertner, S. (2000). A meta-analysis of antecedents and correlates of employee turnover: Update, moderator tests, and research implications for the next millennium. Journal of Management, 26(3), 463-488. doi: Doi $10.1177 / 014920630002600305$ 
Halbesleben, J. R., Neveu, J.-P., Paustian-Underdahl, S. C., \& Westman, M. (2014). Getting to the "COR" understanding the role of resources in conservation of resources theory. Journal of Management, 0149206314527130.

Hobfoll, S. E. (1989). Conservation of resources: A new attempt at conceptualizing stress. American psychologist, 44(3), 513.

Hobfoll, S. E. (2011). Conservation of resources theory: Its implication for stress, health, and resilience. The Oxford handbook of stress, health, and coping, 127-147.

Hobfoll, S. E., \& Freedy, J. (1993). Conservation of resources: A general stress theory applied to burnout.

Holt, D. T., Rehg, M. T., Lin, J. H. S., \& Miller, J. (2007). An application of the unfolding model to explain turnover in a sample of military officers. Human Resource Management, 46(1), 35-49. doi: Doi 10.1002/Hrm.20144

Holtom, B. C., Burton, J. P., \& Crossley, C. D. (2012). How negative affectivity moderates the relationship between shocks, embeddedness and worker behaviors. Journal of Vocational Behavior, 80(2), 434-443. doi: DOI 10.1016/j.jvb.2011.12.006

Holtom, B. C., Mitchell, T. R., Lee, T. W., \& Eberly, M. B. (2008). Turnover and Retention Research: A Glance at the Past, a Closer Review of the Present, and a Venture into the Future. Academy of Management Annals, 2(1), 231-274. doi: Doi $10.1080 / 19416520802211552$

Holtom, B. C., Mitchell, T. R., Lee, T. W., \& Inderrieden, E. J. (2005). Shocks as causes of turnover: What they are and how organizations can manage them. Human Resource Management, 44(3), 337-352. doi: 10.1002/hrm.20074

Hom, P. W., Caranikas-Walker, F., Prussia, G. E., \& Griffeth, R. W. (1992). A metaanalytical strucutral equations analysis of a model of employee turnover. Journal of Applied Psychology, 77(6), 890 - 909.

Hom, P. W., \& Griffeth, R. W. (2013). What Is Wrong With Turnover Research? Commentary on Russell's Critique. Industrial and Organizational PsychologyPerspectives on Science and Practice, 6(2), 174-181. doi: Doi 10.1111/Iops.12029

Hom, P. W., Mitchell, T. R., Lee, T. W., \& Griffeth, R. W. (2012). Reviewing Employee Turnover: Focusing on Proximal Withdrawal States and an Expanded Criterion. Psychological Bulletin, 138(5), 831-858. doi: Doi 10.1037/A0027983

Johal, S. (2015). Kindling Kindness for Compassionate Disaster Management. PLoS currents, 7.

Johal, S., Mounsey, Z., Tuohy, R., \& Johnston, D. (2014). Coping with disaster: General practitioners' perspectives on the impact of the Canterbury earthquakes. PLOS Currents Disasters.

Johns, G. (2006). The essential impact of context on organizational behavior. Academy of Management Review, 31(2), 386-408.

Kaniasty, K. (2012). Predicting social psychological well-being following trauma: The role of postdisaster social support. Psychological Trauma: theory, research, practice, and policy, 4(1), 22.

Kelle, U. (2007). " Emergence" vs." Forcing" of Empirical Data? A Crucial Problem of" Grounded Theory" Reconsidered. Historical Social Research/Historische Sozialforschung. Supplement, 133-156.

Krinsley, K. E., Gallagher, J. G., Weathers, F. W., Kutter, C. J., \& Kaloupek, D. G. (2003). Consistency of retrospective reporting about exposure to traumatic events. Journal of Traumatic Stress, 16(4), 399-409. 
Kulik, C. T., Treuren, G., \& Bordia, P. (2012). Shocks and final straws: Using exit-interview data to examine the unfolding model's decision paths. Human Resource Management, 51(1), 25-46. doi: Doi 10.1002/Hrm.20466

Lee, T. W. (1996). Why employees quit. In L. R. Beach (Ed.), Decision making in the workplace: A unified perspective. (pp. 73 - 91). Mahway: Lawrence Erlbaum Associates, Inc

Lee, T. W., \& Mitchell, T. R. (1994). An Alternative Approach - the Unfolding Model of Voluntary Employee Turnover. Academy of Management Review, 19(1), 51-89. doi: Doi $10.2307 / 258835$

Lee, T. W., Mitchell, T. R., Holtom, B. C., McDaniel, L. S., \& Hill, J. W. (1999). The unfolding model of voluntary turnover: A replication and extension. Academy of Management Journal, 42(4), 450-462. doi: Doi 10.2307/257015

Maertz, C. P., \& Campion, M. A. (1998). 25 Years of voluntary turnover research: A review and critique. In C. L. Cooper \& I. T. Robertson (Eds.), International Review of Industrial and Organizational Psychology. (Vol. 13, pp. 49 - 79). New York: Wiley

Maertz, C. P., \& Campion, M. A. (2004). Profiles in quitting: Integrating process and content turnover theory. Academy of Management Journal, 47(4), 566-582.

March, J. G., \& Simon, H. A. (1958). Organizations. New York,: Wiley.

Mason, M. (2010). Sample size and saturation in PhD studies using qualitative interviews. Paper presented at the Forum Qualitative Sozialforschung/Forum: Qualitative Social Research.

Meyer, J. P., Becker, T. E., \& Vandenberghe, C. (2004). Employee commitment and motivation: a conceptual analysis and integrative model. Journal of Applied Psychology, 89(6), 991.

Mezirow, J. (1990). How critical reflection triggers transformative learning. Fostering critical reflection in adulthood, 1-20.

Mobley, W. H. (1977). Intermediate Linkages in Relationship between Job Satisfaction and Employee Turnover. Journal of Applied Psychology, 62(2), 237-240. doi: Doi $10.1037 / / 0021-9010.62 .2 .237$

Mobley, W. H., Griffeth, R. W., Hand, H. H., \& Meglino, B. M. (1979). Review and Conceptual Analysis of the Employee Turnover Process. Psychological Bulletin, 86(3), 493-522. doi: Doi 10.1037/0033-2909.86.3.493

Morrell, K., \& Arnold, J. (2007). Look after they leap: illustrating the value of retrospective reports in employee turnover. International Journal of Human Resource Management, 18(9), 1683-1699. doi: Doi 10.1080/09585190701570759

Morrell, K., Loan-Clarke, J., Arnold, J., \& Wilkinson, A. (2008). Mapping the decision to quit: A refinement and test of the unfolding model of voluntary turnover. Applied Psychology-an International Review-Psychologie Appliquee-Revue Internationale, 57(1), 128-150. doi: DOI 10.1111/j.1464-0597.2007.00286.x

Morrell, K., Loan-Clarke, J., \& Wilkinson, A. (2004). Organisational change and employee turnover. Personnel Review, 33(2), 161-173. doi: Doi 10.1108/00483480410518022 
Niederman, F., Sumner, M., \& Maertz, C. P. (2007). Testing and extending the unfolding model of voluntary turnover to it professionals. Human Resource Management, 46(3), 331-347. doi: Doi 10.1002/Hrm.20167

Nilakant, V., Walker, B., Rochford, K., \& Van Heugten, K. (2013). Leading in a post-disaster Setting: Guidance for human resource practitioners. New Zealand Journal of Employment Relations (Online), 38(1), 1.

Norris, F. H., Friedman, M. J., Watson, P. J., Byrne, C. M., Diaz, E., \& Kaniasty, K. (2002). 60,000 disaster victims speak: Part I. An empirical review of the empirical literature, 1981-2001. Psychiatry: Interpersonal and biological processes, 65(3), 207-239.

Norris, F. H., \& Kaniasty, K. (1992). Reliability of delayed self-reports in disaster research. Journal of Traumatic Stress, 5(4), 575-588.

Norris, F. H., Stevens, S. P., Pfefferbaum, B., Wyche, K. F., \& Pfefferbaum, R. L. (2008). Community resilience as a metaphor, theory, set of capacities, and strategy for disaster readiness. American Journal of Community Psychology, 41(1-2), 127-150.

Price, J. L., \& Mueller, C. W. (1981). A causal model for turnover for nurses. Acad Manage $J, 24(3)$, 543-565. doi: Doi 10.2307/255574

Purl, J., Hall, K. E., \& Griffeth, R. W. (2016). 12. A diagnostic methodology for discovering the reasons for employee turnover using shocks and events. Research Handbook on Employee Turnover, 213.

Russell, C. J. (2013). Is it Time to Voluntarily Turn Over Theories of Voluntary Turnover? Industrial and Organizational Psychology-Perspectives on Science and Practice, 6(2), 156-173. doi: Doi 10.1111/Iops. 12028

Saldana, J. (2009). The Coding Manual for Qualitative Researchers. London, U.K.: Sage.

Saldana, J. (2012). The coding manual for qualitative researchers: Sage.

Sippel, L. M., Pietrzak, R. H., Charney, D. S., Mayes, L. C., \& Southwick, S. M. (2015). How does social support enhance resilience in the trauma-exposed individual? Ecology \& Society, 20(4).

Steel, R. P. (2002). Turnover theory at the empirical interface: Problems of fit and function. Academy of Management Review, 27(3), 346-360. doi: Doi 10.2307/4134383

Steel, R. P., \& Lounsbury, J. W. (2009). Turnover process models: Review and synthesis of a conceptual literature. Human Resource Management Review, 19(4), 271-282. doi: DOI 10.1016/j.hrmr.2009.04.002

Steers, R. M., \& Mowday, R. T. (1981). Employee turnover and post-decision justification. In L. L. Cummings, \& Straw, B.M. (Ed.), Research in Organizational Behavior. (Vol. 3, pp. 235 - 282). Greenwich: JAI Press

Walker, B., Nilakant, V., \& Baird, R. (2014). Promoting Organisational Resilience through Sustaining Engagement in a Disruptive Environment: What are the implications for HRM? 
Figure 1

\section{Decision Making Process for Deliberate Departers}

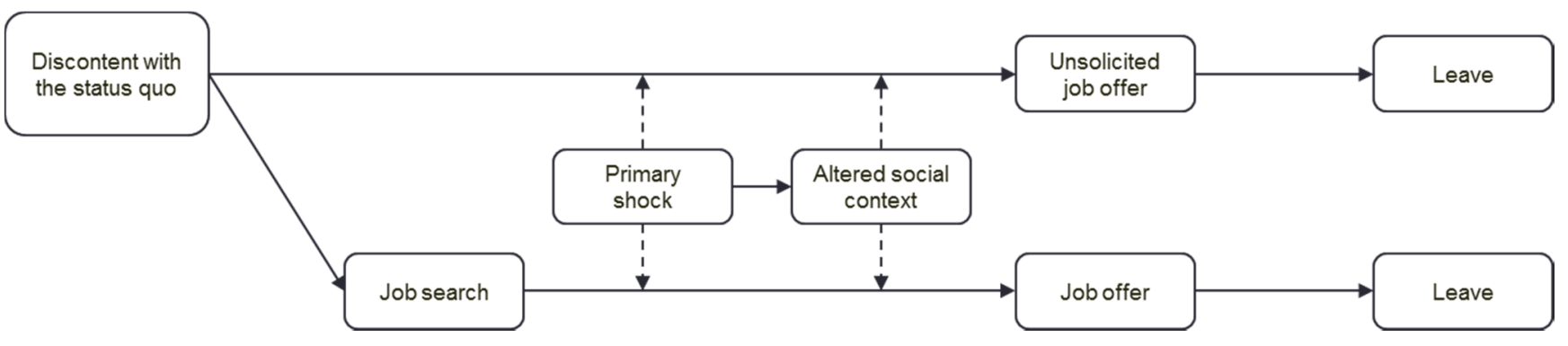

Figure 2

Decision Making Process for New Beginnings

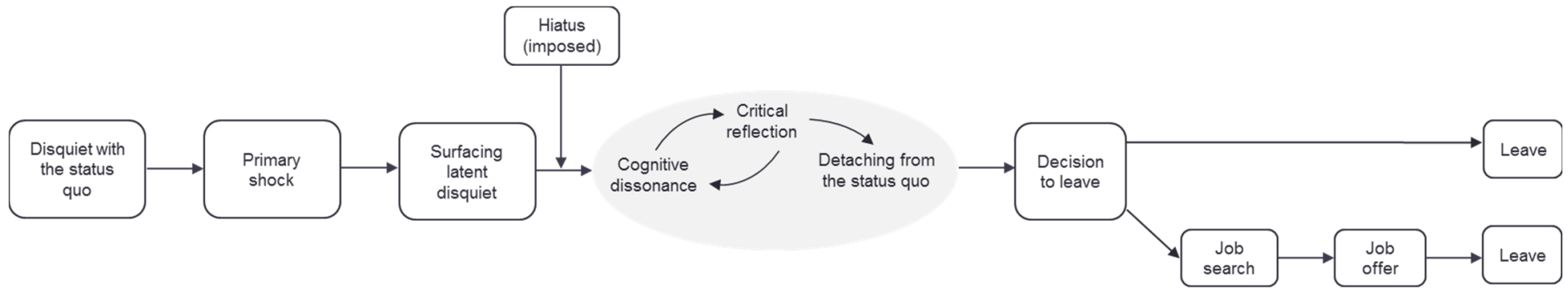

Figure 3

Decision Making Process for Reluctant Departers

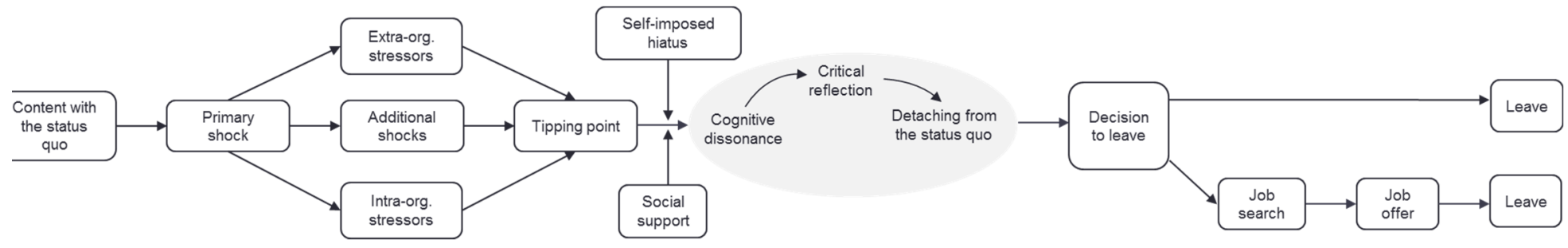

Figure 4

Decision Making Process for Tragic Endings

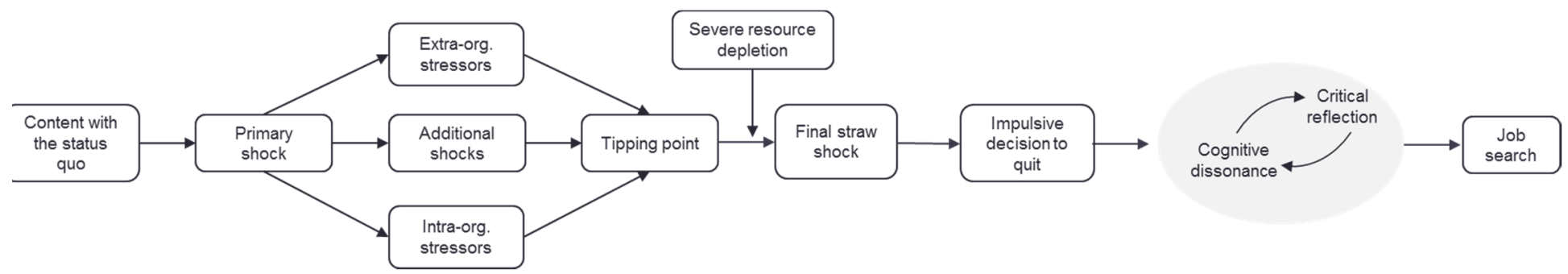

